\title{
EL CULTO AL APÓSTOL SANTIAGO EL MAYOR EN LA CATEDRAL DE SANTIAGO DE CHILE: IMÁGENES Y DOCUMENTOS
}

\author{
THE DEVOTION TO THE APOSTLE SAINT JAMES THE \\ GREAT IN THE CATHEDRAL OF SANTIAGO DE CHILE: \\ IMAGES AND DOCUMENTS
}

\author{
Ana PÉrez VARela \\ Universidad de Santiago de Compostela. España \\ ORCID: 0000-0001-7195-1565 \\ ana.perez.varela@usc.es
}

\begin{abstract}
Este estudio nace de una estancia de investigación en Santiago de Chile en la que nos propusimos recoger todos los ejemplos artísticos del apóstol Santiago el Mayor en la capital que lleva su nombre para poder analizar de qué formas se había representado su imagen a lo largo de la historia e intentar determinar la procedencia de cada ejemplar. Paradójicamente, la historia de esa presencia se convirtió en la historia de su ausencia, al comprobar que las representaciones de Santiago de forma individual en la catedral, más de doscientas parroquias y docenas de conventos y museos suman únicamente nueve, y todas ellas corresponden a obras contemporáneas o importaciones tardías. En este texto nos ocuparemos únicamente de las custodiadas en la fábrica catedralicia, por ser esta la institución que, desde la época colonial, vertebró el culto al Hijo del Trueno.
\end{abstract}

Palabras claves: Santiago el Mayor; Santiago de Chile; culto; iconografía; catedral de Santiago.

This paper is the result of a researching fellowship in Santiago de Chile, where we worked to collect all the artistic examples of the apostle Saint James the Great in the capital, which took his name, in order to analyse his forms of representation thought the History and try to determine the origin of each exemplar. Paradoxically, the history of this presence became the history of his absence, when we corroborated that the images of Saint James as an individual in the Cathedral, more than two hundred parishes and dozens of convents and museums have resulted in a total of nine, and all of them correspond to contemporary examples or late imports. In this text we will take care of the images in the Cathedral, the place that centralized the cult to the Apostle.

Keywords: Saint James the Great; Santiago de Chile; cult; iconography; Cathedral of Santiago. 


\section{INTRODUCCIÓN: LOS SANTIAGOS DE SANTIAGO}

Si hablamos de las representaciones iconográficas de Santiago el Mayor en la capital chilena, lo que más llama la atención es, precisamente, su acusada ausencia. Podríamos pensar que la mayoría de los ejemplos se ha perdido a lo largo de los siglos debido a las vicisitudes históricas entre las que cabe contar numerosos terremotos, incendios, un proceso de independencia con tendencia a rechazar el pasado colonial y, por supuesto, el cambio de moda. Sin embargo, un simple vistazo a las fuentes históricas, crónicas de época, inventarios y descripciones sirve para darnos cuenta de que las representaciones en el pasado fueron igual de escasas. De hecho, no deja de resultar extraño el hecho de que Santiago no tuviese en toda su época colonial una parroquia dedicada al santo que le da nombre ${ }^{1}$.

En toda la urbe, cuajada de conventos, iglesias parroquiales y museos públicos y privados, hemos hallado solamente veinte ejemplos artísticos del Apóstol, y en solo nueve aparece representado de forma individual ${ }^{2}$. Cinco de ellos se encuentran en la catedral y serán protagonistas de este estudio. Otro se encuentra en el Museo Nacional de Bellas Artes y se trata de un matamoros procedente de un retablo realizado hacia mediados del siglo XVII por el llamado Maestro de San Roque en Potosí 3 . También aparece como imagen de bulto redondo en la iglesia parroquial de su titularidad, una escultura española traída a mediados del siglo $\mathrm{XX}^{4}$. La octava la encontramos en un bello esmalte conservado en el Museo

${ }^{1}$ La primera y única iglesia parroquial de Santiago Apóstol en la ciudad data de 1893, como pudimos comprobar en el documento del acta fundacional que se conserva en el templo (Estación Central, calle obispo Manuel Umaña, 396). Nos gustaría agradecer al párroco don David Vera su atención.

2 A estas habría que sumar un octavo ejemplo, tres series iguales de doce grabados al aguafuerte de Patricia Israel creados en 1981 y custodiados en el Museo Nacional de Bellas Artes (SURDOC 2-1149) que representan al apóstol Santiago enlazando su imagen de peregrino con diversos atributos jacobeos y textos poéticos. Se trata de una obra de arte conceptual con otras particularidades que nada tiene que ver con lo que nos proponemos analizar aquí, que son imágenes de culto.

${ }^{3}$ SURDOC 2-3. Se señala como de un escultor anónimo, Maestro de San Roque, identificado como seguidor de Gaspar de la Cueva. Ingresó en el museo con su pareja, el relieve de la Adoración de los Pastores, proveniente del mismo retablo; y fueron un traslado desde el Museo Histórico Nacional, donde carecen de datos de su ingreso. Fue publicada en CRUZ DE AMENÁBAR, Isabel: Arte y sociedad en Chile, 1550-1650. Santiago de Chile, 1986, pp. 237-238; MARTÍNEZ SILVA, Juan Manuel: "El poder de la imagen", en Arte en Chile. Tres miradas. Santiago de Chile, 2014, p. 34; y CRUZ DE AMENÁBAR, Isabel: "Vírgenes milagrosas y primeras tallas virreinales (1550-1650)", en Escultura sacra patrimonial en Santiago de Chile. Siglos XVI a XX. Santiago de Chile, 2016, pp. 31-33.

${ }^{4}$ La ficha correspondiente puede consultarse en el Inventario de Bienes Parroquiales de la Iglesia en Chile, un proyecto llevado a cabo por la Universidad Adolfo Ibáñez y el arzobispado, que tuvimos la oportunidad de consultar íntegramente gracias a doña Patricia 
Nacional de Artes Decorativas, obra europea de la época moderna ${ }^{5}$. Finalmente, existe una pequeña estatua pétrea conmemorativa, donación española de 2005, situada en la Plaza de Armas ${ }^{6}$.

El resto de obras hasta completar la veintena, se refiere a su aparición en series de apostolados, que, si bien son interesantes para estudiarlas desde un punto de vista iconográfico, no pueden considerarse como una representación intencionada de rendir homenaje a la figura de Santiago. A continuación analizaremos las imágenes conservadas en la actualidad en la catedral, teniendo en cuenta tanto los ejemplos individuales como los apostolados. De todas las obras mencionadas, ninguna ha salido de talleres chilenos.

\section{LAS IMÁGENES QUE EXISTEN: OBRAS CONSERVADAS ACTUALMENTE EN LA CATEDRAL}

\section{El antiguo retablo del altar mayor}

El altar mayor actual data de la remodelación de 1913, cuando las obras del presbiterio adelantaron la situación de este unos metros con respecto al original ${ }^{7}$. El retablo anterior todavía se marca acoplado a la actual pared trasera de la fábrica, consistente en una estructura de arco serliano sustentado por cuatro columnas corintias. Aparece la Asunción en el centro, Santiago a su derecha y Santa Rosa de Lima en el lado opuesto. La figura del peregrino, olvidada por la historiografía ${ }^{8}$, aparece vestido con túnica y manto, sosteniendo el bordón sin calabaza en la mano

Silva (arzobispado de Santiago). Esta escultura se corresponde con la Zona Oeste, ficha 8095. La información sobre la procedencia de la imagen nos fue proporcionada por el párroco actual. No existe ningún registro documental al respecto y la talla no presenta características que nos permitan ubicarla en una escuela española concreta, ya que se trata de una imagen industrial en serie.

${ }^{5}$ SURDOC 24-266. Está catalogada como pieza europea de los siglos XVI o XVII. Ingresó en el museo como parte de la colección de Hernán Garcés Silva, por lo que quizás fuese adquirida en el siglo XX por el coleccionista, y no se importase a Santiago en la época. No hemos hallado referencias bibliográficas.

${ }^{6}$ Esta ostenta un marcado eco de modelos medievales románicos, y enlaza por lo tanto con una estética que evoca las representaciones primitivas del Apóstol en su propia catedral de Santiago de Compostela.

7 ACS (Archivo de la Catedral de Santiago de Chile), Inventario, 1913, f. 55. En este artículo haremos referencia en reiteradas ocasiones a los inventarios catedralicios, que hemos tenido la oportunidad de consultar gracias a doña Carmen Pizarro.

${ }^{8}$ No lo hemos hallado mencionado en ningún texto. Querejazu Leyton no lo recoge en su estudio sobre figuras de Santiago en Chile. LEYTON, Pedro: "Santiago en la pintura y escultura de Bolivia, Chile y Perú", en Santiago y América. Santiago de Compostela, 1993, pp. 163-179. 
izquierda y el libro en la mano derecha (Figura 1). Está en actitud de contemplación, con la mirada dirigida a la Virgen de la Asunción y los brazos abiertos. A excepción del bordón, carece de los atributos típicos del peregrino.

Creemos que la figura de la Asunción que todavía se conserva es la encargada en 1864 a Adolfo Bihourd bajo la prelatura de Valdivieso Zañartu (1847-1878), mencionada por Delpiano del Río, ya que se referencia como un altorrelieve de madera que quedaría adherido al muro solamente por la espalda, suspendido a unos diez metros 9 . Teniendo en cuenta la documentación catedralicia, creemos que Bihourd era un intermediario que se encargaba de contactar talleres en Francia y despachar las obras hasta el puerto de Valparaíso ${ }^{10}$. A juzgar por la armonía estilística, las figuras de Santiago y Santa Rosa debieron acompañar a la Asunción, y creemos que fueron encargadas al mismo taller y en la misma época. En ellas se repiten las características estipuladas por el prelado al encargar la Asunción: rostro y carnaciones de color natural y ropaje dorado. Esta Virgen ha sido referida como del ámbito de Saint-Sulpice, del último cuarto del siglo XIX ${ }^{11}$.

La imagen llegó de Valparaíso en agosto de 1865. En el inventario catedralicio de 1863 se había aludido a "una imagen vieja del Tránsito que se ponía en el altar mayor", lo que nos indica que ya se había desinstalado de su lugar la figura antigua para colocar la nueva imagen francesa. Una anotación posterior nos indica que esta Asunción anterior se regaló a una iglesia parroquial ${ }^{12}$.

El primer inventario en el que aparecen mencionadas las nuevas figuras es el de 1871, donde se dice que "todo el grupo de la Asunción está dorado, excepto el rostro de la Virgen y los ángeles. Hay cuatro grandes estatuas más: las del Apóstol Santiago i de santa Rosa de Lima que coronan las columnas i dos ángeles adoradores, todas doradas e iluminadas como las anteriores"13. La misma información se repite en 1875, donde además se añade que se intervino en ellos con una reforma, pintando y dorando el conjunto ${ }^{14}$. Veinte años después, en 1895, el inventario se vuelve a referir a ellas ${ }^{15}$. En 1902 hubo de intervenirse de algún modo en las figuras, ya que en las cuentas y comprobantes se registra un pago por "bajar y subir estatuas de santos en el altar mayor"16.

${ }^{9}$ DELPIANO DEL RÍO, María Angélica: "Dos arzobispos creativos que perduran en la Historia", en Iconografia, identidad nacional y cambio de siglo (XIX-XX). Jornadas de Historia del Arte en Chile. Santiago de Chile, 2003, p. 64.

${ }_{10}$ Agradecemos la orientación de don Fernando Guzmán en este asunto.

${ }^{11}$ DÍAZ VIAL, Claudio: Escultura sacra patrimonial en Santiago de Chile, siglos XVI al $X X$. Santiago de Chile, 2016, p. 187.

12 ACS, Inventario, 1863, f. 43.

13 ACS, Inventario, 1871, f. 2.

14 ACS, Inventario, 1875, ff. 4 y 68.

15 ACS, Inventario, 1895, f. 57.

16 ACS, Cuentas y comprobantes, 24-5-1902, recibo 22. 
No tenemos más noticia sobre este espacio hasta que en 1913 se coloca el nuevo tabernáculo ${ }^{17}$. Este fue construido por los talleres Franz Mayer de Múnich, una casa con gran fortuna artística en la capital chilena ${ }^{18}$. Nada se menciona sobre las figuras del antiguo retablo, que quedaron olvidadas en la pared trasera.

\section{El altar lateral}

Una segunda figura de Santiago está emplazada en un altar neoclásico de madera policromada de finales del siglo XIX (Figura 2). Esta obra se enmarca en un estilo rico y ampliamente decorado, siguiendo las pautas marcadas por el cabildo eclesiástico para la decoración del interior catedralicio a finales del siglo XIX, a base de coloridos estucados que hicieron que Roa Urzúa se refiriese a la actuación como "una cruel profanación del templo a base de pintarrajeados yesos" ". Posteriormente, en este artículo, trataremos de determinar qué existía como capilla de Santiago antes de la instalación de este altar.

La figura construida en madera policromada también es una obra del ámbito de los talleres parisinos de Saint-Sulpice. Se ha relacionado a menudo con otras tres esculturas catedralicias que representan a la Inmaculada Concepción, San Pedro y el Sagrado Corazón. Las dos primeras están documentadas como obras de los talleres escultóricos Maison Verrebout, llevadas a cabo en 1887, presentadas en París ante el obispo Casanova y Casanova, y enviadas a Chile al año siguiente $^{20}$. Nosotros creemos que debemos atrasar la instalación de esta figura a la segunda mitad de la década de los noventa. Al referirnos a la historia del culto a Santiago en la catedral, indicaremos porqué.

El Apóstol aparece representado en su iconografía habitual de peregrino estático, descalzo, con túnica y manto elegantemente plegados, bordón con calabaza en la mano izquierda y rollo epistolar en la derecha. Carece de sombrero o esclavina, pero como símbolo distintivo, presenta una concha de venera en forma de broche prendiendo el manto.

\section{El apostolado de los pilares}

Dispuesto en los pilares de la nave central encontramos un grupo de dieciocho figuras, entre las que se encuentra un apostolado, los cuatro evangelistas, el rey David y Moisés. Tenemos constancia de que anteriormente, en el mismo

17 ACS, Inventario, 1913, f. 55.

${ }_{18}$ DÍAZ VIAL, Claudio: Escultura sacra patrimonial..., op. cit., pp. 226-235.

19 ROA URZÚA, Luis: El arte en la época colonial de Chile. Santiago de Chile, 1929, p. 28.

${ }^{20}$ DÍAZ VIAL, Claudio: Escultura sacra patrimonial..., op. cit., pp. 186-192. 
lugar, se había colocado el apostolado en óleo de $\mathrm{Ambrosi}^{21}$, del que hablaremos a continuación, y también, en otro momento, una secuencia de esculturas de apóstoles hoy perdidas ${ }^{22}$. Las estatuas actuales se encargaron a Francia en 1867 bajo la prelatura de Valdivieso, también a través de Bihourd. En una carta de Juan Miguel Arrate dirigida al contratista, se demandan figuras de 220 centímetros realizadas en madera dorada excepto las carnaciones en color natural. Sobre ellas se indica: "No se pretende obra original sino una buena copia de estatua o pintura de maestro antiguo o moderno" 23 .

A finales del mismo año el cabildo escribió a Francisco Fernández Rodella, residente en París, para que llevase a cabo un encargo de figuras al escultor chileno Nicanor Plaza, imponiéndole las características de las que ya estaban realizadas. Sin embargo, Plaza no se quiso hacer responsable de la obra, que recayó finalmente en manos de otros artistas que no conocemos ${ }^{24}$. Una nota añadida al inventario de 1868 nos indica: "seis estatuas doradas venidas de Europa, representando a los apóstoles san Pedro, san Pablo, Santiago el Mayor, San Andrés, san Juan y santo Tomás, colocadas sobre las repisas de la nave del medio"25. Eso nos indica que las dos primeras remesas de estatuas llegaron a lo largo de 1868. En enero de 1869 se encargaron, también a través de Fernández Rodella, una estatua de Santiago el Menor y otra de San Felipe. Estos dos apóstoles llegaron en 1870 junto con San Mateo ${ }^{26}$. En el inventario de 1875 se señala la presencia de catorce estatuas, pero todavía faltaban cuatro ${ }^{27}$. Finalmente, en 1876 se encargaron las figuras de Moisés, David, San Marcos y San Lucas, realizadas en la Casa Froc Robert a Fils de París. Estas llegaron en 1886. Teniendo en cuenta las noticias de los diferentes encargos, cabría revisar que la casa parisina Froc Robert a Fils realizó el conjunto completo de figuras ${ }^{28}$. Pese a que el grupo guarda una unidad estilística, no es difícil advertir distintas manos.

De bulto redondo y acopladas a la pared, las figuras se encuentran sustentadas por elegantes ménsulas y enmarcadas por una moldura de arco de medio

${ }^{21}$ ACS, Inventario, 1845, f. 22.

${ }^{22}$ En el inventario de 1913 se señala la presencia en las dependencias catedralicias de dos figuras "talladas en madera de los apóstoles que estaban en la nave central de la $\mathrm{Ca}$ tedral antes de la transformación de Ignacio Cremonesi, tamaño menor que natural, del siglo XVIII, propiedad de las hermanas de la Misericordia de Maipo”. ACS, Inventario, 1913, f. 28.

${ }^{23}$ DELPIANO DEL RÍO, María Angélica: "Dos arzobispos creativos...”, op. cit., pp. 66-68.

${ }^{24}$ Ibidem.

${ }_{25}$ ACS, Inventario, 1868, p. 96.

${ }^{26}$ DELPIANO DEL RÍO, María Angélica: "Dos arzobispos creativos...”, op. cit., pp. 66-68.

${ }^{27}$ ACS, Inventario, 1875, p. 16.

${ }^{28}$ DÍAZ VIAL, Claudio: Escultura sacra patrimonial..., op. cit., pp. 186-187. 
punto coronada por una gran cartela oval enmarcada con volutas que presenta los nombres de cada personaje. Santiago el Mayor se encuentra ubicado en la arcada del lado de la epístola, en el segundo pilar a contar desde el altar mayor (Figura 3). Presenta la iconografía de peregrino estático, descalzo, con túnica ampliamente plegada, esclavina, bordón con calabaza en la mano izquierda y libro en la mano derecha. Ostenta cabello y barba rizados y nimbo. Enfrente, en el pilar parejo, encontramos la figura de Santiago el Menor. Con respecto al altar mayor, solo cuenta con una posición más cercana la pareja de San Pedro y San Pablo.

Roa Urzúa señala la llegada en 1898 de un estucador italiano, "que había embadurnado la iglesia matriz de Talca", al que el arzobispo Casanova y Casanova (1886-1908) le encargó la decoración del interior catedralicio a pesar, según el escritor, de las voces que se alzaron contra ello, especialmente por parte del periódico El Mercurio. Urzúa advierte que las elegantes piedras talladas en forma de concha sobre las que reposaban las figuras de los pilares de la nave central fueron destruidas y sustituidas por soluciones de hierro y estuco ${ }^{29}$.

La filiación parisina hace que podamos comparar este apostolado con el ubicado en la iglesia de la Preciosa Sangre, también en Santiago, que se mueve en la misma órbita cronológica y estilística ${ }^{30}$. Es de destacar en este ejemplo parroquial la expresividad de Santiago, extrañamente calvo, de cuyo cuello prende el sombrero de peregrino con vieiras. Para nosotros, este grupo es de mejor calidad que el de la catedral. Los apóstoles presentan mayor fortuna de posturas, actitudes y gestualidad facial, además de ropajes más vistosos, cromáticamente más ricos y con vestimentas más variadas.

\section{El apostolado en óleo}

Con la expulsión de los jesuitas de todos los territorios de la corona en 1767 durante el gobierno de Carlos III, la catedral y los principales centros religiosos de Santiago se nutrieron de un extraordinario tesoro artístico que pasó por ser una de las mejores expresiones del arte sacro colonial de Chile ${ }^{31}$. Entre los tesoros jesuitas, llegó a la fábrica este apostolado al óleo conservado en la sacristía, procedente del colegio Máximo de San Miguel, la iglesia hoy desaparecida debido al incendio de 1863. Son obra del jesuita Joseph Ambrosi y fueron realizadas en 1766. Tanto el autor como la fecha quedan constatados en las firmas que

${ }^{29}$ ROA URZÚA, Luis: El arte en..., op. cit., p. 20.

${ }^{30}$ DÍAZ VIAL, Claudio: Escultura sacra patrimonial..., op. cit., p. 196.

${ }^{31}$ Para ampliar información sobre el arte jesuita en Chile y la diseminación de su patrimonio tras la Expulsión, vid. PEREIRA SALAS, Eugenio: Historia del Arte en el reino de Chile. Santiago de Chile, 1965, pp. 80-ss. 
aparecen en los cuadros correspondientes a San Pedro, San Pablo, Santiago el Menor y, precisamente, Santiago el Mayor ${ }^{32}$.

Las obras están ceñidas por marcos que imitan la textura marmórea con adornos de rocalla dorados. Representan a los doce apóstoles, el Salvador y la Inmaculada de medio cuerpo, situados tras la repisa lígnea que sirve de apoyo a las figuras y las enmarca en un espacio diferente al del espectador, a la vez que sirve como soporte para tallar el nombre indicativo de cada personaje. Todos aparecen siguiendo modelos convencionales de representación, en un amplio catálogo de gestos y posturas - destaca la gestualidad de las manos en diferentes actitudes-, traspasando o no la repisa, leyendo, pensativos o hieráticos, portando cada uno el instrumento de su martirio.

Como ha estudiado Porres Benavides, el modelo para estos cuadros lo encontramos en una serie de grabados de Hendrick Goltzius ${ }^{33}$, "uno de los más destacados burilistas del primer barroco flamenco" ${ }^{34}$. El pintor jesuita siguió de este modo la tónica habitual contrarreformista de buscar modelos iconográficos en las series de grabados que circularon en la época por Europa y América, especialmente procedentes del mundo flamenco ${ }^{35}$. La serie del apostolado de Goltzius, conocida como el "Credo corto" $(1589)^{36}$, se convirtió en uno de los modelos más difundidos en la España del barroco, no solo en Andalucía, donde Navarrete Prieto señaló un gran número de obras ${ }^{37}$, sino en todo el territorio ${ }^{38}$.

${ }^{32}$ PORRES BENAVIDES, Jesús: "Las pinturas del Apostolado de la Sacristía de la Catedral de Santiago de Chile", en El sistema de las artes. VII Jornadas de Historia del Arte. Santiago de Chile, 2014, pp. 79-80.

${ }^{33}$ La Virgen, identificada como "Regina Apostolorum", no pertenece a la serie de Goltzius. Se relaciona, según Porres Benavides, con grabados como el "Salus Infirmorum" del libro Litaniae Lauretanae grabado por Joseph Sebastián y Johan Baptist Klauver (Augsburgo, 1750). PORRES BENAVIDES, Jesús: "Las pinturas del Apostolado...", op. cit., p. 86.

${ }^{34}$ Ibidem, p. 80.

${ }^{35}$ CRUZ DE AMENÁBAR, Isabel: Arte y sociedad..., op. cit, p. 57.

${ }^{36}$ Las series de apóstoles conocidas como "Credo" se refieren a un orden específico en función de la oración textual que los acompaña - un verso del credo en cada apóstol-y son abundantes en la iconografía contrarreformista.

${ }^{37}$ De hecho, al señalar que también fue habitual que los autores copiasen solo una estampa para inmortalizar a un santo individual, Navarrete Prieto indica que fue Santiago el Mayor el más reproducido. NAVARRETE PRIETO, Benito: La pintura andaluza del siglo XVII y sus fuentes iconográficas. Madrid, 1998, pp. 153-156. Existe un estudio, realizado por Martínez Yuste, específico para la provincia de Málaga. MARTÍNEZ YUSTE, María: "La influencia de Hendrick Goltzius en los apostolados en la provincia de Málaga", en Cultura simbólica. Estudios. Málaga, 2014, pp. 85-103.

${ }^{38}$ Existen otros ejemplos entre los que destaca el óleo del Zebedeo de la iglesia de Santiago de Astorga, publicado en GONZÁLEZ GARCÍA, Miguel Ángel: "La iconografía del apóstol en Astorga", Compostellanum, 34, 1989, p. 413. 
Casi todos los cuadros de Ambrosi siguen exactamente el modelo de Hendrick Goltzius, variando ligeramente las posturas, añadiendo los nimbos y sustituyendo el fondo paisajístico característico del grabador flamenco por sobrios fondos oscuros que hacen que la figura se recorte en claroscuro. La pintura del Santiago, correspondiente al verso III del Credo, "QVI CONTEPTVS EST DE SPIRITV SANCTO, NATVS EX MARIA VIRGINE”, copia de manera bastante fiel el modelo de Goltzius (Figura 4). Santiago reposa la cabeza en su brazo derecho y sostiene el bordón con su mano izquierda. La vestimenta difiere ligeramente en estilo. Goltzius le coloca una túnica y una capa en cuya solapa se dispone la concha de vieira, de plegados recortados, detallistas y volumétricos. El ropaje en Ambrosi es más plano, pero también presenta la vieira. Lleva un sombrero de peregrino de ala ancha decorada con una alternancia de conchas y un motivo con dos espadas cruzadas, cabellos y barba larga. Ambrosi suprime el elemento iconográfico del libro cerrado.

Goltzius presenta un rostro más melancólico, inclinado hacia abajo, con la mirada dirigida fija en el espectador. El de Ambrosi es más hierático y frontal; y la gestualidad de las manos, la calidad textil o la representación de las carnaciones y cabellos es mucho más torpe en el pintor jesuita. De hecho, la desproporción de las manos llevó a Araneda Bravo a pensar que se trataba de una parte mal retocada por un pintor restaurador ${ }^{39}$. Pereira Salas distingue a Santiago expresivamente del resto de apóstoles: "de decididos rasgos naturalistas [...] tiene las facciones firmes de una realidad que contrasta con el conjunto de las demás telas"40. Otros autores coinciden en señalar que el Santiago es uno de los mejores cuadros de la serie ${ }^{41}$.

\section{El apostolado en cobre}

En las dependencias de la sala capitular hemos encontrado un apostolado pintado al óleo sobre láminas de cobre de clara filiación italiana al que la historiografía no ha prestado atención, a pesar de que las obras constituyen un ejemplo de gran calidad dentro del imaginario catedralicio. La iconografía del apóstol Santiago está en consonancia con los modelos italianos del siglo XVII, cuando tiende a depurarse de los rasgos del peregrino y a adquirir una imagen

${ }^{39}$ ARANEDA BRAVO, Fidel: Historia de la iglesia en Chile. Santiago de Chile, 1986, p. 266.

${ }^{40}$ PEREIRA SALAS, Eugenio: Historia del Arte en el reino de Chile. Santiago de Chile, 1965, p. 102.

${ }^{41}$ CRUZ DE AMENÁBAR, Isabel: Lo mejor de la historia de la pintura y escultura en Chile. Santiago de Chile, 1984, p. 92. Véase también QUEREJAZU LEYTON, Pedro: "Santiago en la...", op. cit., p. 170; y la ficha catalográfica CRUZ DE AMENÁBAR, Isabel: "Santiago peregrino", en Santiago y América. Santiago de Compostela, 1993, p. 396, cat. 114. 
más universal en la que solo conserva el bordón (Figura 5). Hemos observado modelos parecidos en la Roma de mediados del seiscientos. Un Santiago de similares características, obra de Romanelli, fue publicado por Vázquez Santos ${ }^{42}$. En este momento estamos profundizando en el estudio de esta serie para lograr proponer una escuela y cronología más aproximada. Creemos que su calidad merece un estudio individualizado.

Las dos únicas noticias que hemos encontrado al respecto son las de los inventarios catedralicios y la de Roa Urzúa. En los documentos, aparecen en el inventario de 1913 -curiosamente, no lo hacen antes- como "un apostolado en cobre, italiano, en marcos venecianos del siglo XVIII, en regular estado", colocados en la sala capitular ${ }^{43}$. En el inventario de 1974 encontramos esta anotación: "doce cuados al óleo de los apóstoles pintados por Ambrosi, colocados en marcos venecianos de madera, bronce y espejuelos. Dos cuadros (el Salvador del Mundo y la Santísima Virgen), también de Ambrosi en marcos venecianos. Los catorce cuadros descritos tienen vidrio" 44 . Creemos que el anotador se equivoca al referirse a los óleos de Ambrosi cuando en realidad está hablando de estos. En primer lugar, porque están ubicados en la sala capitular. En segundo lugar, por la descripción del marco y por el hecho de que tengan cristal protector, de lo cual carecen los lienzos jesuitas. En tercer lugar, porque más adelante, al inventariar la sacristía, menciona catorce cuadros del Apóstol, la Virgen y el Salvador, con "marcos de madera tallados, con dorado al fuego y pintados", esta vez sin mencionar autor. Estos sí serían los de Ambrosi ${ }^{45}$.

Urzúa relaciona la serie con el obispo Alday y Aspée (1753-1788), quien las legó a la catedral a mediados del siglo XVIII. Los describe como "catorce pinturas en láminas de cobre, encuadradas en valiosos marcos de bronce y cristales dibujados", sin indicar autor o escuela ${ }^{46}$. Este es el único dato que los ubica en la catedral en el siglo XVIII, ya que como hemos dicho, no aparecen en los inventarios hasta 1913.

${ }^{42}$ Fue pintado para el altar mayor de San Giacomo in Settignana en el segundo tercio del siglo XVII. VÁZQUEZ SANTOS, Rosa: "Santiago el Mayor en el barroco romano. Rusconi, Maratti, Romanelli", Cuadernos de arte e iconografía, 30, 2006, p. 292; y VÁZQUEZ SANTOS, Rosa: "Primeras conclusiones sobre el culto y la iconografía de Santiago el Mayor en la ciudad de Roma”, Archivo Español de Arte, 329, 2010, p. 14. Agradecemos el conocimiento de esta referencia a nuestro compañero Javier Gómez Darriba.

43 ACS, Inventario, 1913, f. 36.

${ }_{44}$ ACS, Inventario, 1974, f. 17.

${ }^{45}$ Ibidem.

${ }^{46}$ ROA URZÚA, Luis: El arte en..., op. cit., p. 20. 


\section{La fachada principal}

Otra representación del Zebedeo la encontramos no en el interior de la catedral, sino decorando su exterior. La figura del Santiago peregrino situada coronando la calle lateral izquierda de la fachada catedralicia fue incorporada en el proyecto de remodelación de Ignacio Cremonesi, llevado a cabo entre 1898 y 1906 (Figura 6). Está situado flanqueando a la patrona, la Virgen de la Asunción, sita en la calle central; y en el lado opuesto a Santa Rosa, repitiendo la secuencia de imágenes del antiguo retablo mayor. La estatua, que tiene aproximadamente cuatro metros de alto y está realizada en metal, probablemente fuese traída de Italia junto con sus dos compañeras. Presenta la tradicional iconografía del peregrino estático, descalzo, con túnica y manto de elegantes plegados, bordón con calabaza y rollo epistolar. Es de destacar la presencia de Santiago vigilando desde lo alto la Plaza de Armas, espacio emblemático de la ciudad, donde confluyen las esferas sacra y civil. Junto con la pequeña escultura del Santiago peregrino neorrománico de 2005, serían dos los Santiagos que podemos observar desde este lugar.

\section{Otras representaciones en la catedral}

Entre la colección de artes decorativas que alberga la catedral, hemos encontrado también un estandarte textil protagonizado por el apóstol Santiago (Figura 7). Carecemos de información sobre su origen, autoría o datación, y nada hemos hallado al respecto en bibliografía o la documentación del archivo catedralicio. Creemos que fue creado para las festividades del 25 de julio en algún momento reciente, en la segunda mitad del siglo XX. En todo caso, ya existía en 1974 como demuestra el inventario, que lo describe como "un estandarte rojo del apóstol Santiago, bordado de oro"47. Quizás está en relación con la recuperación de la tradición del paseo del estandarte el día del Santiago, costumbre a la que posteriormente aludiremos. En todo caso hoy está en desuso.

En la pieza aparece el santo en su iconografía de peregrino, pero en postura orante, única en su modelo entre las representaciones en la ciudad. Aparece nimbado, con túnica, manto y esclavina con vieiras, el bordón del que cuelga el sombrero de ala ancha, y un rosario colgando de su muñeca derecha, un atributo extraño en un Santiago. La escena está enmarcada en un óvalo ceñido por delicados entrelazados vegetales de tipo grutesco, salpicados de flores de colores y centrados en una vieira dorada.

Encontramos un último Santiago dentro de las dependencias catedralicias. Se trata del vaciado de la escultura de la fachada realizado en yeso y pintado en dorado, que se emplea en las actuales celebraciones del 25 de julio en la fábrica para ser colocado en el altar mayor (Figura 8). Tampoco tenemos datos sobre su

${ }^{47}$ ACS, Inventario, 1974, f. 11.

LABORATORIO DE ARTE 31 (2019), pp. 185-208, ISSN 1130-5762 e-ISSN 2253-8305 - DOI http://dx.doi.org/10.12795/LA.2019.i31.11 
autoría o fecha, pero sabemos que también existía en 1974. En el inventario se le describe como "una imagen del apóstol Santiago (yeso dorado) con su pedestal", ubicado en la referida como "Sala de Sesiones del Apóstol Santiago"48.

\section{LAS IMÁGENES QUE EXISTIERON: NOTICIAS DEL CULTO A SANTIAGO EN LA CATEDRAL}

Como ya hemos indicado, tenemos la seguridad que desde 1865 existió una figura de Santiago en el retablo del altar mayor, conservada todavía hoy en día en el muro trasero. También sabemos que existió un altar lateral de Santiago por lo menos desde que se instaló - creemos que a finales de la década de los noventa del siglo XIX-, proveniente también del ámbito de Saint-Sulpice. Pero con anterioridad a estas fechas, ¿existían figuras de Santiago en la catedral que recibiesen culto en el altar mayor y su propio altar lateral? Sanfuentes argumentó la presencia de una imagen del Zebedeo a caballo en la catedral, teniendo en cuenta que una de las actividades centrales en la fiesta del Apóstol era la procesión con la imagen ecuestre en andas de Santiago ${ }^{49}$. Sin embargo, no sabemos cómo era ni cuántas hubo a lo largo del tiempo. Veamos las noticias que nos ha dejado la documentación y la historiografía.

A principios del siglo XVII, el cabildo acusaba, en una carta dirigida al rey, la falta grave de ornamentos que impedía que se llevase a cabo el culto ${ }^{50}$. Cincuenta años desde el inicio de su construcción -en la década de los sesenta del siglo XVI-, la fábrica todavía no tenía altar, sino que se señalaba "una imagen de Nuestra Señora de la Victoria, a la que vendría a acompañar más tarde una imagen de Santiago" "51. Creemos que esta figura del Apóstol es la que regaló el capitán Pedro Portillo en 1626, que fue traída del convento de San Agustín. Al año siguiente, también existe noticia del encargo de un lienzo de Santiago para colocar en la sala capitular, costeado por el corregidor Diego González Montero ${ }^{52}$. Tenemos por lo tanto constancia en un primer momento de una imagen del Apóstol en el epicentro de la basílica, acompañando a la Virgen, ejemplo que en todo caso se ha perdido, pero que nos demuestra al menos la iniciativa de colocar al patrón de la ciudad en el lugar religioso más importante de la misma.

${ }^{48}$ Ibidem, f. 13.

${ }^{49}$ CRUZ DE AMENÁBAR, Isabel: "Vírgenes milagrosas y...”, op. cit., p. 33; y SANFUENTES, Olaya: "Santiago en Santiago. Desde una devoción religiosa-militar hacia una celebración cortesano-cívica", Revista de Indias, 274, 2018, p. 636.

${ }^{50}$ CRUZ DE AMENÁBAR, Isabel: Arte y sociedad en..., op. cit., p. 193.

${ }^{51}$ RAMÓN ACEVEDO, Emma: La obra y su proceso: historia de la fábrica de la catedral de Santiago, 1541-1769. Tesis doctoral, Pontificia Universidad Católica de Chile, 2000, pp. 112-113.

52 CRUZ DE AMENÁBAR, Isabel: Arte y sociedad en..., op. cit., p. 209. 
Durante el obispado de fray Gaspar de Villarroel, en 1643, se menciona la existencia de altares consagrados a San José y San Antonio, y dos imágenes de Nuestra Señora de la Victoria y San Pedro, instaladas en el altar mayor ${ }^{53}$. También destaca la presencia de una capilla de Santiago, con una imagen proporcionada por el cabildo, pero sin precisar su ubicación ${ }^{54}$. Por lo tanto, parece ser que esa estatua que existió en el altar mayor unas décadas atrás se había quitado para rendirle culto individual en su propia capilla o altar lateral.

En el terrible terremoto de 1647 se perdió todo el adorno interior. En los trabajos de ornamentación de las reconstrucciones, se menciona la ejecución de un altar de San Pedro, a imagen de dos ya existentes advocados a la Purísima y a Santa Rosa de Lima ${ }^{55}$. En la relación de altares que se van rehaciendo nada se dice del de Santiago.

En 1670 tenemos noticia de la construcción de un bello sagrario para el altar mayor decorado con varias imágenes, entre ellas San Pedro, San Pablo, los doctores de la Iglesia y la Virgen de la Victoria. La linterna de ocho nichos ostentaba seis de ellos vacíos, por encontrarse la iglesia falta de imágenes. Los dos únicos huecos ocupados se adornaban con las figuras de San Pedro y Santiago el Mayor $^{56}$. La imagen del Apóstol volvió así a estar representada en el altar principal.

En 1730 y 1751 tuvieron lugar nuevos terremotos. En 1755 los nuevos altares laterales fueron dorados por Ignacio Leyton, y entre ellos se menciona uno de Santiago Apóstol ${ }^{57}$. Por si los seísmos fuesen poco, en 1769 ardió la catedral destruyéndose por completo. Parece que solo pudo salvarse una Virgen próxima a la Puerta del Perdón ${ }^{58}$. En 1775, tenemos noticia del trabajo de Pascual Bohórquez en cuatro retablos, entre ellos el de Santiago Apóstol ${ }^{59}$.

Sabemos que, a finales del siglo XVIII, el entallador Bernardo Godoy llevó a cabo los retablos dorados de la catedral en el proyecto de reconstrucción de Joaquín Toesca, hoy también perdidos tras la remodelación de Ignacio Cremonesi $(1898-1909)^{60}$. Uno de ellos hubo de ser el de Santiago. En 1816, Sanfuentes documentó los gastos realizados en una estatua de Santiago, de cuya naturaleza se deduce que era un ejemplo del Apóstol a caballo ${ }^{61}$. A partir de esa fecha contamos con inventarios conservados en el archivo de la catedral, y en el primero

${ }^{53}$ RAMÓN ACEVEDO, Emma: La obra y..., op. cit., p. 117.

${ }^{54}$ CRUZ DE AMENÁBAR, Isabel: Arte y sociedad en..., op. cit., p. 201.

${ }^{55}$ RAMÓN ACEVEDO, Emma: La obra y..., op. cit., p. 136.

${ }^{56}$ Ibidem, p. 129.

57 PEREIRA SALAS, Eugenio: Historia del Arte..., op. cit., p. 126.

${ }^{58}$ RAMÓN ACEVEDO, Emma: La obra y..., op. cit., p. 179.

59 PEREIRA SALAS, Eugenio: Historia del Arte..., op. cit., p. 129.

${ }^{60}$ CRUZ DE AMENÁBAR, Isabel: Arte y sociedad en..., op. cit., p. 186.

${ }^{61}$ SANFUENTES, Olaya: "Santiago en Santiago...", op. cit., pp. 653-654. 
disponible, de 1829, se menciona un bulto de "Santiago Apóstol en su altar" 62 . Este altar debe ser el construido por Godoy.

La misma figura se menciona en un inventario sin fecha, pero comprendido entre 1829 y 1837, como "el señor Santiago en su altar". Una anotación a posteriori titulada "Objetos [...] que el Cabildo decidió vender", se menciona la estatua del apóstol Santiago. Sin embargo, no podemos precisar la fecha en la que se llevó a cabo este añadido y creemos que la venta se refiere al momento en el que llegó la estatua de Saint-Sulpice a finales de siglo, ya que se menciona la venta de prácticamente todas las imágenes de bulto de la fábrica. Esto no podría explicarse de no ser por una remodelación completa de los altares como la acometida a finales del siglo XIX con la llegada del aparato ornamental francés ${ }^{63}$. De hecho, en el inventario de 1837 se vuelven a mencionar todos los bultos que se indican vendidos en la anotación, incluido "el señor Santiago en su altar" 64 . En los inventarios posteriores se sigue mencionando "una imagen del señor Santiago, colocada en su altar" 65 .

Lo que resulta más interesante es la partida de "una imagen del apóstol Santiago que salía antiguamente a caballo", mencionada en el inventario de 1868 además de la propia de su altar latera ${ }^{66}$. Estamos hablando de la existencia, todavía a finales del siglo XIX, de una imagen del matamoros - que no se menciona en los inventarios anteriores-, a la que se le había rendido culto en procesión en algún momento del pasado.

La imagen del altar lateral se sustituyó poco después por un lienzo, como demuestra una lista de añadidos al inventario, en el que se señala la adquisición de "un cuadro del Apóstol Santiago colocado en su altar" ${ }^{67}$. En el inventario de 1871 se dan más detalles al respecto del altar: "es también de madera i colocado dentro del arco de piedra que hai en la muralla". Más interesantes resultan los datos que añade sobre los lienzos: "cuatro cuadros que representan a los tutelares de la Arquidiócesis. El del apóstol Santiago ocupa el fondo o centro del altar i representa al Apóstol, entre cadenas, marchando a la muerte". Estaríamos hablando por lo tanto de una iconografía inédita en la capital chilena y muy extraña en las

${ }^{62}$ ACS, Inventario, 1829 , ff. 66/45v. La numeración doble que puede aparecer en alguna referencia a los folios se refiere a la doble paginación de algunos documentos, que fueron revisados y reordenados posteriormente.

${ }^{63}$ ACS, Inventario, s. f. (a continuación de Inventario, 1829), ff. 75/54r. Tenemos motivos para creer que esta anotación es bastante posterior al manuscrito del inventario, basándonos en apreciaciones que hace la misma persona - con la misma caligrafía y tipo de tinta- a lo largo de la documentación conservada en la catedral.

${ }^{64}$ ACS, Inventario, 1837, ff. 86/64r.

${ }^{65}$ ACS, Inventario, 1845, f. 22; 1863, f. 43; y 1868, f. 67.

${ }_{66}$ ACS, Inventario, 1868, f. 67.

${ }^{67}$ Ibidem, f. 96. 
representaciones tradicionales del santo. Se alude también a tres medallones representando al mártir San Saturnino, San Francisco Solano y San Antonio de Padua. Resulta muy curiosa la referencia a una reliquia íntegra del cuerpo de San Marcos que se veneraba en el altar de Santiago ${ }^{68}$. No tenemos constancia de la existencia de una reliquia jacobea en ningún momento de la historia de la ciudad.

El inventario de 1875 repite la misma información ${ }^{69}$. Sin embargo, resulta de gran interés la mención de un cuadro colocado en una de las naves laterales, que representaba la aparición de la Virgen del Pilar a Santiago el Mayor en Zaragoza $^{70}$. Aunque no han llegado hasta nosotros, junto con el Santiago encadenado estaríamos hablando de dos episodios de la vida del Apóstol conservados en la catedral a finales del siglo XIX con iconografías inéditas en la ciudad. El mismo año también se alude a un cuadro del apóstol Santiago, retratado de forma individual "al costado de la puerta de la sacristía, como de metro i medio, con marco dorado"71. El documento menciona también una imagen de bulto del Apóstol, vestida $^{72}$, lo que significa que, pese a que el altar lateral ya no custodiaba la figura sino los lienzos, esta todavía no se había vendido, por lo que estaríamos hablando de por lo menos seis representaciones individuales del Apóstol en la catedral ${ }^{73}$. En una nota añadida se señala que fue vendida una "imagen del apóstol Santiago, de esqueleto"74.

El inventario de 1895 repite la misma información sobre los cuadros de su retablo, por lo que creemos que el nuevo altar de los talleres Saint-Sulpice no llegó a finales de la década de los ochenta ${ }^{75}$ sino de los noventa. Ese mismo año se indica en una anotación de 1939, que las pinturas de San Saturnino y San Francisco Solano se destruyeron porque "era[n] de mala factura, nada valía[n]"76. No sabemos la suerte que corrió la de Santiago encadenado. Este mismo año de 1895 vuelve a

${ }_{68}$ ACS, Inventario, 1871, f. 4.

${ }^{69}$ ACS, Inventario, 1875, ff. 5-6.

${ }^{70}$ Ibidem, f. 14.

${ }^{71}$ Ibid. Ya nos hemos referido a la única noticia de un encargo de un lienzo del Apóstol en 1627 para colocar en la sala capitular costeado por el corregidor Diego González Montero. Creemos que es muy complicado que se trate de este óleo, teniendo en cuenta las continuas destrucciones de obra, especialmente en el incendio de 1769.

${ }^{72}$ Ibid., f. 63.

${ }^{73}$ Nos referimos a la escultura del retablo del altar mayor, la vieja imagen de su altar lateral, el lienzo de Santiago encadenado que la sustituyó, el lienzo de la aparición de la Virgen del Pilar en una de las naves, el lienzo del Apóstol de la puerta de la sacristía, y el matamoros.

74 Ibid., f. 68. Desconocemos la fecha de esta anotación, pero en todo caso debió ser posterior a 1895, porque el inventario de ese año (ACS, Inventario, 1895, f. 124) todavía la menciona.

${ }^{75}$ DÍAZ VIAL, Claudio: Escultura sacra patrimonial..., op. cit., pp. 186-192.

${ }^{76}$ ACS, Inventario, 1895, f. 49. 
mencionarse el cuadro de la Virgen del Pilar y Santiago ${ }^{77}$, que fue definitivamente retirado dos años después con motivo de la construcción del mausoleo del arzobispo Valdivieso ${ }^{78}$, y también se alude a una del apóstol Santiago y a la del Santiago matamoros "que no tiene[n] uso y puede[n] venderse"79.

En 1904, el altar íntegro de Santiago se donó a la parroquia de Colina, por indicación del arzobispo ${ }^{80}$, lo cual resulta lógico teniendo en cuenta que ya se había instalado el nuevo altar francés.

En 1913, se menciona por primera vez el nuevo altar de Santiago, de madera pintado y dorado, pero se referencia como "era antes de la Virgen del Rosario". Probablemente el altar francés que llegó a finales del XIX, se empleó en primer lugar para instalar a la Virgen del Rosario, y finalmente se cambió la imagen por la de Santiago. Más importante es la afirmación "tiene una buena estatua de madera, decorada, la que se encargó a Europa para la procesión del patrono de la ciudad" ", lo que nos indica que a principios del siglo XX se seguía celebrando una procesión con la imagen del santo, destacando su condición de patrón de la capital. No se conservan más inventarios a lo largo del siglo XX en el que se mencione la figura.

En resumen, las noticias sobre imágenes de Santiago en la catedral a lo largo de la historia son escasas, pero permiten confirmar que siempre se mantuvo cierto culto en torno a una figura escultórica, tanto en el altar mayor como en su propio altar lateral. Creemos que las vicisitudes sufridas por la fábrica impidieron que tuviese ininterrumpidamente una capilla o altar en un mismo lugar. En todo caso, hoy día este ocupa el primero de la nave lateral del evangelio desde la puerta de entrada, aunque su figura ya no recibe el culto festivo procesional que sí tuvo antaño.

\section{UN BREVE APUNTE SOBRE LA FIESTA DE SANTIAGO}

Tenemos constancia de que la fiesta de Santiago, el 25 de julio, se celebró en la capital durante el periodo colonial y desde la temprana fecha de $1556^{82}$, siendo probablemente la primera festividad en ponerse en escena en Santiago ${ }^{83}$. Dentro

\footnotetext{
${ }^{77}$ Ibidem, f. 57.

78 Ibid., f. 122.

79 Ibid., f. 126.

${ }^{80}$ ACS, Actas Capitulares, XVII, 30-9-1904.

${ }^{81}$ ACS, Inventario, 1913, f. 87.

${ }^{82}$ De este año data la primera mención en las actas del cabildo, cuando la fiesta se instaura al llegar la cédula que concede las armas de la ciudad. VALENZUELA MÁRQUEZ, Jaime: Las liturgias del poder. Celebraciones estratégicas y persuasivas en Chile colonial (1609-1709). Santiago de Chile, 2001, p. 322.

${ }^{83}$ CRUZ DE AMENÁBAR, Isabel: "Santiago: una fiesta patronal al sur del mundo", Historia y Cultura, 23, 1994, p. 263.
} 
de las estrategias de dominación cultural puestas en marcha por el gobierno español, el día pasó a formar parte de ese particular uso político de la fiesta en la colonia, como mecanismo de dominación y asimilación, mantenida durante siglos $^{84}$. Santiago pasó a identificarse de forma directa como el símbolo nuclear de la hispanidad castellana, en inmediata relación con la monarquía, el Imperio y la conquista ${ }^{85}$.

En un primer momento la fiesta se celebró con gran pompa, entre fastuosos festejos que incluyeron corridas de $\operatorname{toros}^{86}$ y el Paseo del Estandarte Real. Esta tradición fue el símbolo festivo por excelencia en relación a la monarquía hispánica, y se celebró en la colonia unido a diferentes festividades religiosas. En el caso de Santiago, esta costumbre se estableció el día de la fiesta de su patrón. Bien documentada por González Avendaño ${ }^{87}$ y Valenzuela Márquez ${ }^{88}$, y ampliamente estudiada por Cruz de Amenábar ${ }^{89}$ y Sanfuentes ${ }^{90}$, esta fiesta se traspasó directamente de la costumbre homóloga castellana. El estandarte, símbolo del poder monárquico y civil -y llevado por el alférez escoltado por los alcaldes-, acompañaba en la procesión a la figura de Santiago en andas, símbolo del poder eclesiástico -y por tanto, portado por el cabildo-. De este modo, la fiesta de Santiago se convirtió en una simbiótica celebración y ostentación pública de los dos poderes más importantes de la esfera social en la colonia. A su vez, Santiago era el santo patrón de la monarquía española, alimentando más esta relación entre ambas dimensiones. Con respecto al propio textil, y dependiendo de la cronología, en algunos casos se habla de las armas de la ciudad y de la monarquía ${ }^{91}$, y en otros, de la figura de Santiago matamoros ${ }^{92}$.

${ }^{84}$ ACOSTA DE ARIAS, Rosa María: Fiestas coloniales urbanas. Lima-Cuzco-Potosí. Lima, 1997, p. 37.

${ }^{85}$ Sobre la construcción del discurso identitario de Santiago como símbolo del poder monárquico y militar, véase ALMEIDA FRAGA, Andrés: El apóstol Santiago en Chile. Imaginería de reconquista y discurso providencial. Siglo XVI. Tesis de Licenciatura inédita, Pontificia Universidad Católica de Chile, 2002, especialmente pp. 47-55.

${ }^{86}$ GONZÁLEZ ESTÉVEZ, Escardiel y SANFUENTES, Olaya: "Los toros de Santiago de Chile durante el periodo colonial", Anuario de Estudios Americanos, 74, 2017, p. 127-154.

${ }^{87}$ GONZÁLEZ AVENDAÑO, Julio: "Santiago apóstol y el paseo del estandarte real en Chile", Boletín de la Academia Chilena de la Historia, 52, 1955, pp. 133-148.

88 VALENZUELA MÁRQUEZ, Jaime: Las liturgias de..., op. cit.

${ }^{89}$ CRUZ DE AMENÁBAR, Isabel: "Santiago: una fiesta...", op. cit, pp. 259-274; y CRUZ DE AMENÁBAR, Isabel: La fiesta. Metamorfosis de lo cotidiano, Santiago, 1995, pp. 158-164.

90 SANFUENTES, Olaya: "Santiago en Santiago...”, op. cit., pp. 633-658.

91 VALENZUELA MÁRQUEZ, Jaime: Las liturgias de..., op. cit., p. 322.

${ }^{92}$ GONZÁLEZ AVENDAÑO, Julio: "Santiago apóstol y...”, op. cit., pp. 133-148. 
Paulatinamente, la celebración fue apagándose, algo que se evidencia si ana-

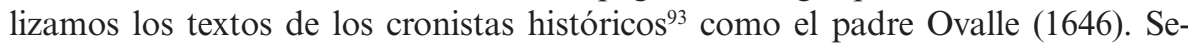
gún se deduce de su texto, el día de Santiago pasó, a lo largo de la primera mitad del siglo XVII, a ser una fecha no especialmente destacada dentro del calendario de festividades litúrgicas santiaguinas, decayendo su importancia como principal evento en favor del Corpus Christi ${ }^{94}$. Como estudió Sanfuentes, la fiesta pasó de tener una raíz medieval y caballeresca en los siglos XVI y XVII, a una cortesana, propia del contexto ilustrado, en el siglo XVIII ${ }^{95}$. Durante esta centuria, el componente de exaltación monárquica de la fiesta fue tomando más fuerza, resultando en una fiesta predominantemente civil y motivando su decadencia por oposición de la sociedad santiaguina a la propia idea de exaltación idólatra a la monarquía ${ }^{96}$.

Según Toribio Medina, en 1796 se instituyó una multa de cincuenta pesos para el vecino que no concurriese a la fiesta, lo que puede indicar que esta había ido perdiendo importancia con el paso del tiempo y que el absentismo era importante ${ }^{97}$. En 1816 se llevó a cabo el último Paseo del Estandarte, no exento de polémica en plena Reconquista española ${ }^{98}$.

La fiesta decayó todavía más tras la declaración de la Independencia por su vinculación con esta idiosincrasia colonial y con la monarquía ${ }^{99}$, y los esfuerzos por recuperarla a partir del siglo XIX, especialmente por parte del arzobispo Valdivieso, no hallaron eco en la sociedad santiaguina ${ }^{100}$. Desde la instauración institucional de la devoción de la Virgen del Carmen por el libertador O'Higgins, esta advocación mariana fue ocupando el lugar del Apóstol ${ }^{101}$. Como ya hemos

${ }^{93}$ Nada dicen de ella Jerónimo de Vivar (1558), Góngora y Marmolejo (1575), Sánchez de Espinosa (ca. 1625), Melchor Jufré (1630), Diego de Rosales (ca. 1650), Juan Ignacio Molina (1776), Carvalho y Goyeneche (1796) o Enrique Espinoza (1890).

${ }^{94}$ El religioso reseña el Corpus Christi como la más importante de las celebradas en la colonia, seguida de la Semana Santa. También alude a la suntuosidad con la que se celebraban las fiestas relacionadas con acontecimientos reales -nacimiento, coronación, desposorios, etc.-, canonizaciones de santos o las fiestas de la Purísima Concepción, mandadas festejar con gran pompa por orden real. Y ya al referirse a "otras festividades", menciona la del día de Santiago. DE OVALLE, Alonso: Historia relación del reyno de Chile. Roma, 1646, pp. 163-169.

${ }^{95}$ SANFUENTES, Olaya: "Santiago en Santiago...", op. cit., pp. 652-654.

${ }^{96}$ CRUZ DE AMENÁBAR, Isabel: La fiesta. Metamorfosis..., op. cit., pp. 161-164.

${ }^{97}$ TORIBIO MEDINA, José: Cosas de la colonia. Apuntes para la crónica del siglo XVIII en Chile. Santiago de Chile, 1952 (edición príncipe: Santiago de Chile, 1889), p. 102.

${ }^{98}$ CRUZ DE AMENÁBAR, Isabel: "Santiago: una fiesta...", op. cit., p. 271.

99 VALENZUELA MÁRQUEZ, Jaime: Fiesta, rito y politica: del Chile borbónico al republicano. Santiago de Chile, 2014, p. 275.

${ }^{100}$ CRUZ DE AMENÁBAR, Isabel: "Vírgenes milagrosas y...”, op. cit., p. 33.

101 GONZÁLEZ ESTÉVEZ, Escardiel y SANFUENTES, Olaya: "Los toros de...", op. cit., p. 132, nota 14 . 
referido, el estandarte carmesí que se realizó en algún momento antes de 1974, evidencia un intento de recuperación de la festividad tradicional en el siglo XX, que hoy ha quedado reducida a una misa ${ }^{102}$.

\section{CONCLUSIONES}

En este artículo hemos pretendido exponer una relación de todas las imágenes de Santiago que se conocen en la actualidad en el centro neurálgico de su culto: la catedral. Teniendo en cuenta las vicisitudes sufridas por la fábrica, que hicieron que la mayor parte de las imágenes que conservamos sean recientes, hemos aportado noticias sobre posibles imágenes de Santiago que existieron en la fábrica santiaguina desde que se conserva documentación, así como algún apunte sobre su fiesta, que dejó de celebrarse en el ocaso de la colonia. A través de este ejercicio hemos podido comprobar que las imágenes son escasas, pero que siempre se mantuvo cierto culto al Apóstol en la catedral, más o menos centrado en un altar propio, cuya existencia fue intermitente a lo largo de los siglos. También hemos demostrado la presencia de imágenes con iconografía historiada de temática jacobea, que lamentablemente se han perdido, pero que hubiesen constituido ricos e interesantes ejemplos del patrón en una ciudad donde hallar imágenes de este es, paradójicamente, tarea complicada.

Reflexionar acerca del proceso de emancipación republicana de las imágenes y la posible consecuencia de ausencia de imágenes de Santiago requeriría otro artículo aparte; y más, cuando parece que las imágenes del Apóstol fueron igualmente escasas en época colonial ${ }^{103}$. Pero es innegable que los nuevos postulados alentados por la mentalidad ilustrada arremetieron contra las estructuras históricas coloniales, viejas y gastadas, cuestionando todo lo español y revalorizando los cimientos culturales propios y autóctonos. En palabras de Cruz de Amenábar: "Chile comenzó así un proceso de emancipación donde el mensaje cultural

102 Aunque a partir de 1558 el estandarte se estableció como de damasco azul, parece que los primeros años se realizó en color carmesí (VALENZUELA MÁRQUEZ, Jaime: Las liturgias de..., op. cit., pp. 322 y 349, nota 777), por lo que este ejemplo recuperaría la tradición primigenia.

${ }^{103}$ Resulta llamativo que, en el rastreo de los inventarios de todos los edificios conventuales y parroquiales existentes en la época de colonia que hemos examinado en nuestra estancia, no se mencione ni una sola vez una imagen del apóstol Santiago, teniendo en cuenta que las capillas de culto e imágenes de bulto de las cuales hemos hallado noticia son numerosísimas. Algunos de estos personajes referenciados están en correspondencia lógica con los santorales de cada orden. Sin embargo, otros muchos nombres resultan extraños y con un culto muy minoritario. Es sorprendente que en ningún momento se decidiese dedicar un pequeño altar o una figura del patrón de la ciudad en ningún convento o iglesia de la ciudad. 
barroco iba a ser sustituido por una nueva idiosincrasia"104. En esta nueva dimensión política y cultural que había cambiado para siempre la mentalidad colectiva del país, no tenía cabida una fiesta que venerase al dios guerrero que había ayudado a los españoles a masacrar a los indígenas.

Fecha de recepción: 30 de octubre de 2018

Fecha de aceptación: 1 de julio de 2019

104 Ibidem, pp. 37-38. 


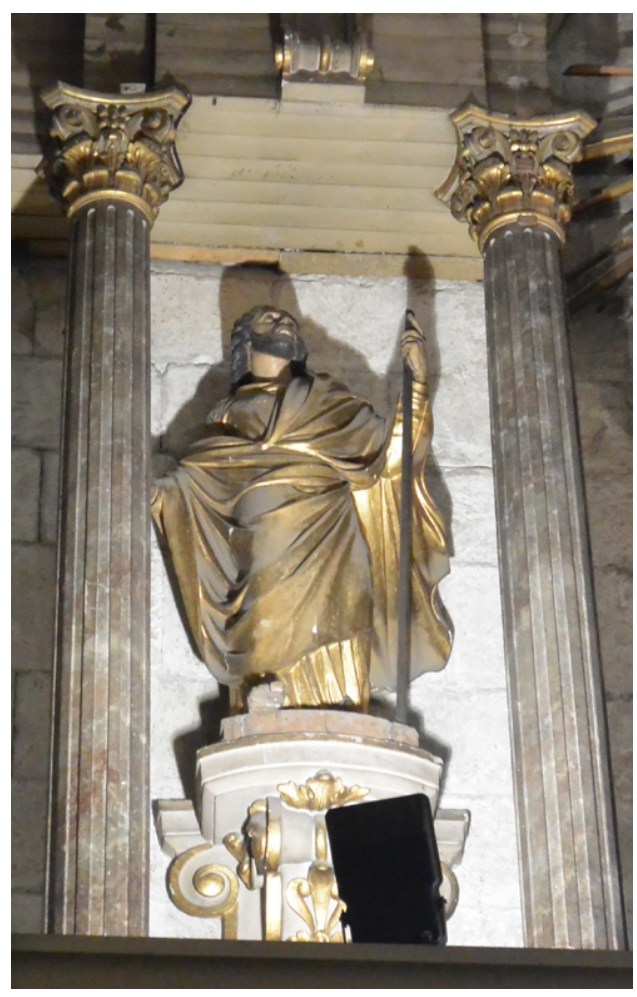

Figura 1. Ámbito de Saint-Sulpice, Santiago Apóstol del antiguo altar mayor, ca. 1865, catedral de Santiago de Chile.

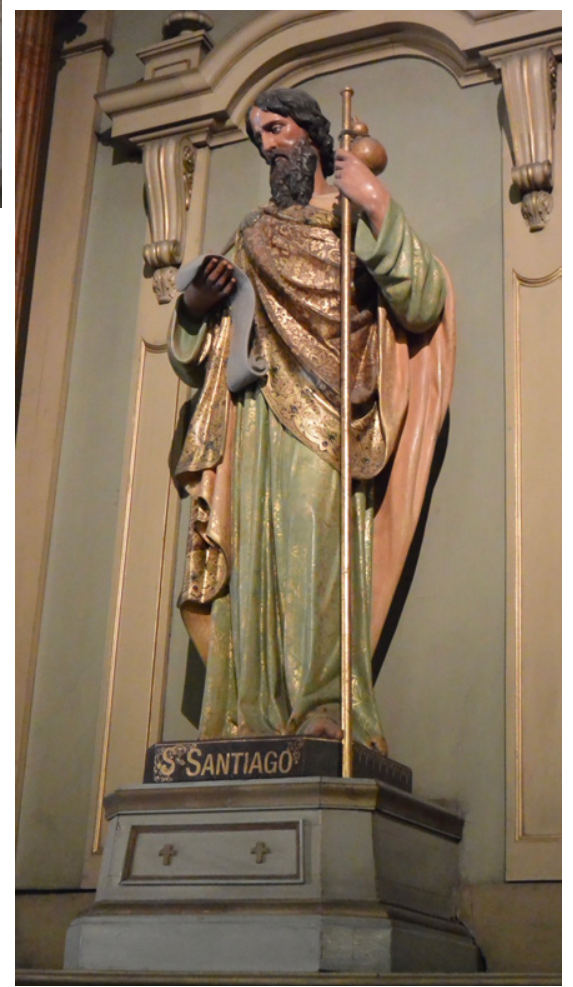

Figura 2. Ámbito de Saint-Sulpice, Santiago Apóstol del altar lateral, ca. 1895, catedral de Santiago de Chile. 


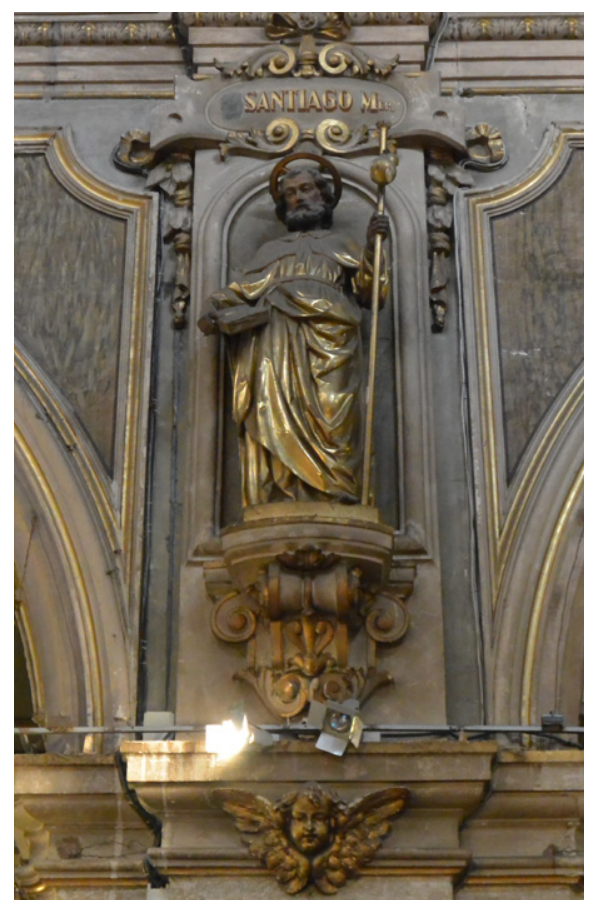

Figura 3. Ámbito de Saint-Sulpice, Santiago Apóstol del pilar de la nave central, ca. 1867, catedral de Santiago de Chile.

Figura 4. Joseph Ambrosi, Santiago Apóstol, 1766, sacristía de la catedral de Santiago de Chile.

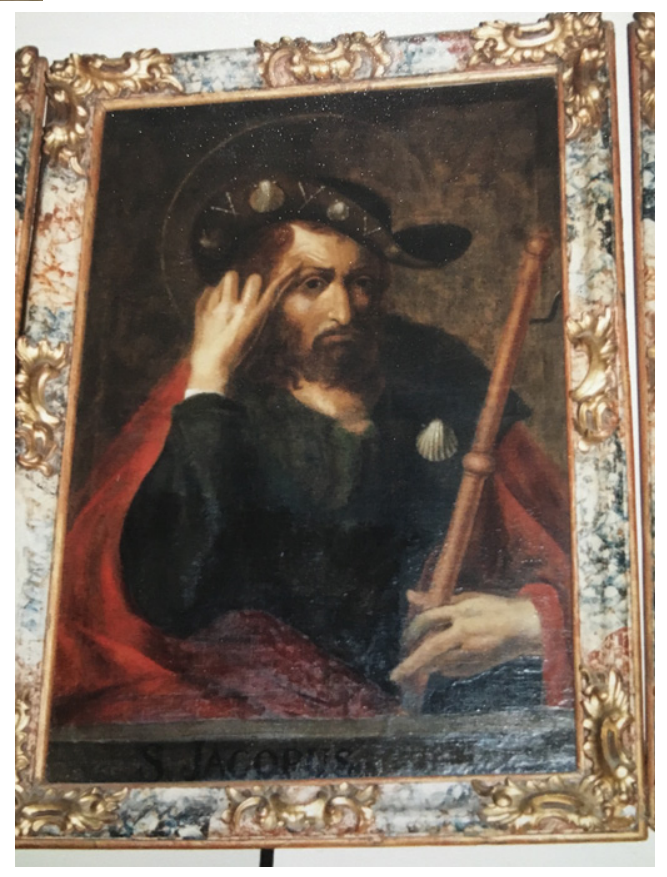

LABORATORIO DE ARTE 31 (2019), pp. 185-208, ISSN 1130-5762

e-ISSN 2253-8305 - DOI http://dx.doi.org/10.12795/LA.2019.i31.11 
Figura 5. Anónimo, Santiago Apóstol, siglo XVII, sala capitular de la catedral de Santiago de Chile.

Figura 6. Anónimo, Santiago Apóstol, ca. 1898-1906, fachada de la catedral de Santiago de Chile.
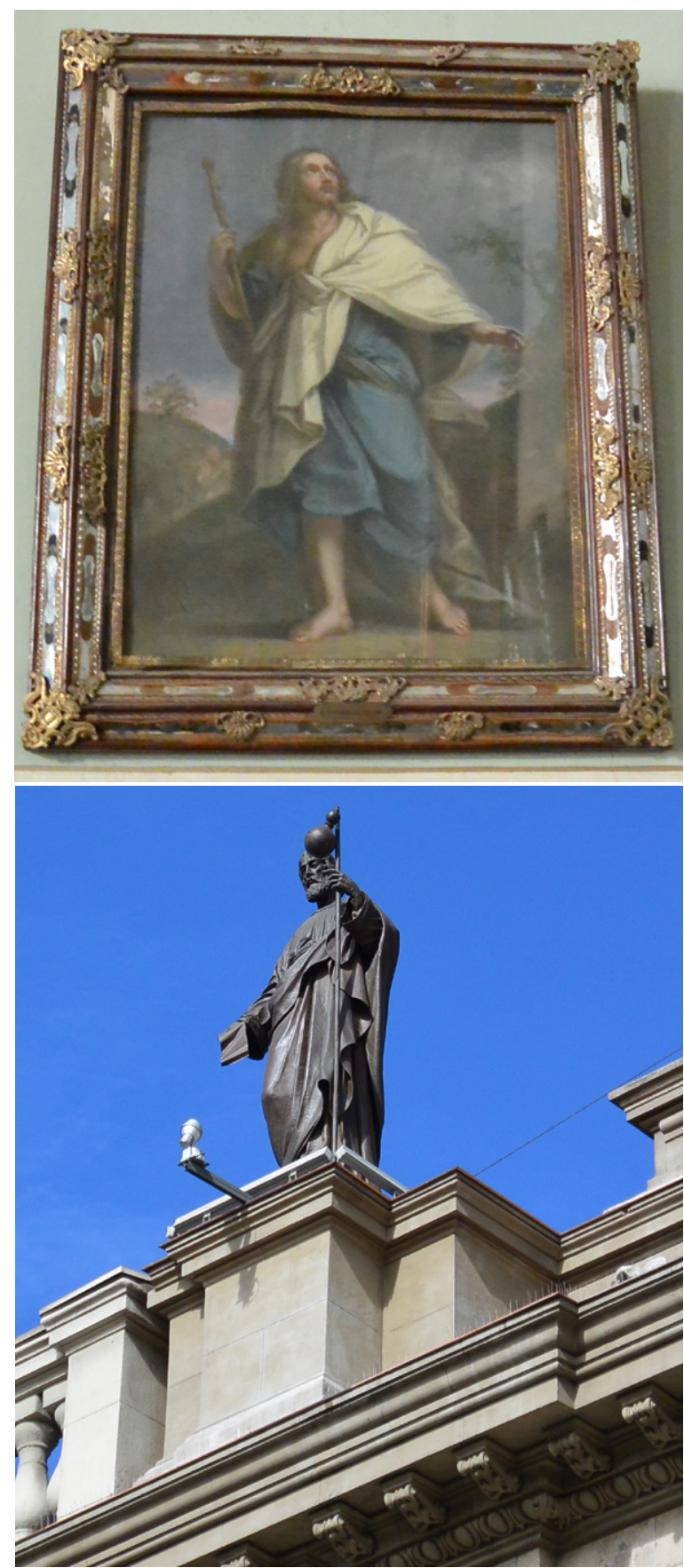

LABORATORIO DE ARTE 31 (2019), pp. 185-208, ISSN 1130-5762 e-ISSN 2253-8305 - DOI http://dx.doi.org/10.12795/LA.2019.i31.11 


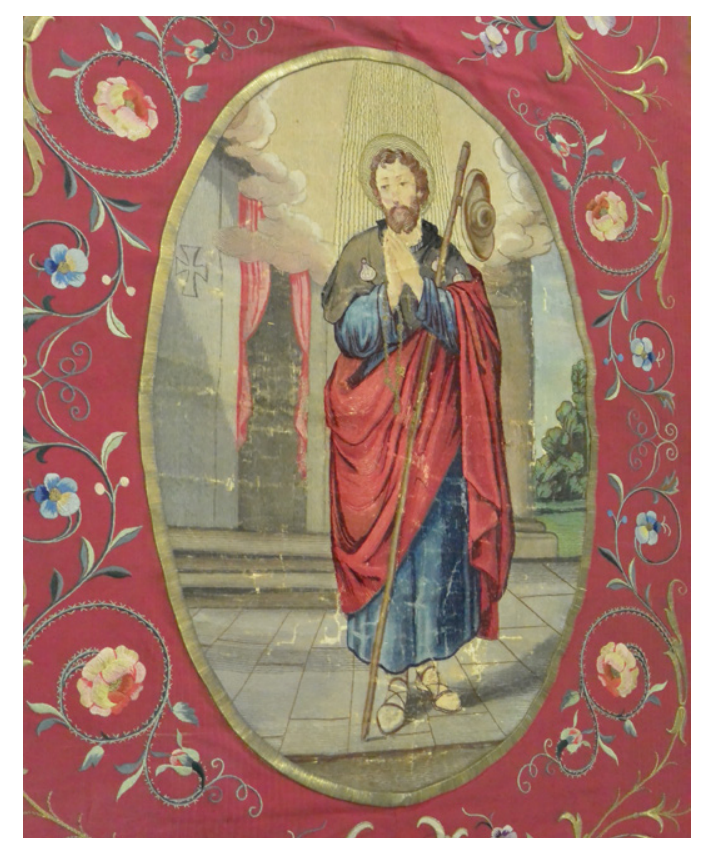

Figura 7. Anónimo, Estandarte de Santiago Apóstol, antes de 1974, catedral de Santiago de Chile.

Figura 8. Anónimo, Santiago Apóstol, antes de 1974, catedral de Santiago de Chile.

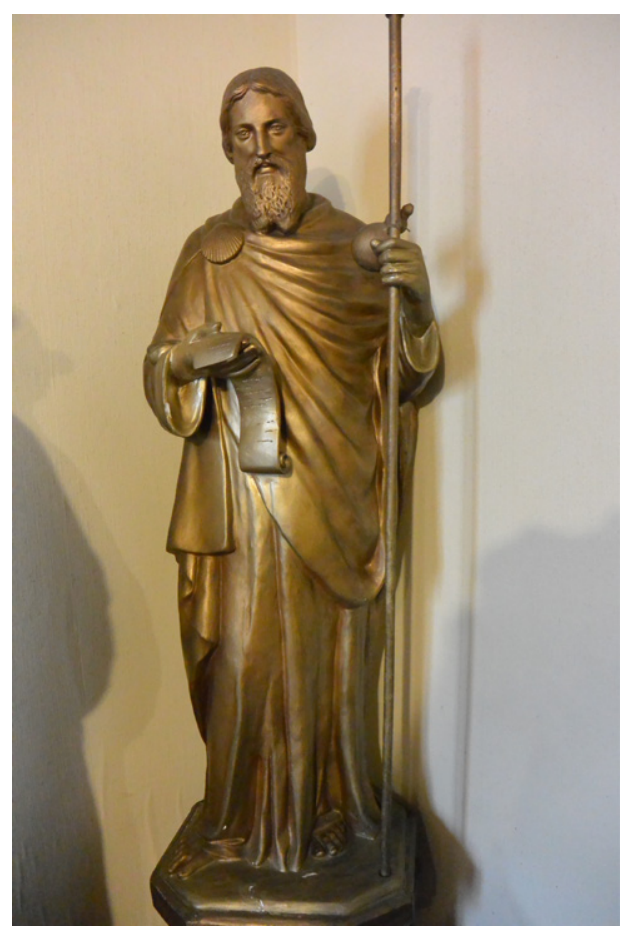

